\title{
Erratum to: Individual and Contextual Effects of School Adjustment on Adolescent Alcohol Use
}

\author{
Kimberly L. Henry $\cdot$ Linda R. Stanley • \\ Ruth W. Edwards • Lindsey C. Harkabus • \\ Laurie A. Chapin
}

Published online: 19 August 2010

(C) Society for Prevention Research 2010

Erratum to: Prev Sci (2009) 10:236-247

DOI 10.1007/s11121-009-0124-2

The original version of this article unfortunately contained two typographical errors. The first occurs on page 241, the final sentence in the first paragraph of the second column. The sentence should read: We calculated the within-school and between-school $\mathrm{R}^{2}$ using the formulas offered by Snijders and Bosker (1999). These estimates indicate that $4.0 \%$ of the variance in level 1 alcohol scores and $27.0 \%$ of the variance in level 2 alcohol scores is predicted by the covariates in Model 1. The second occurs in Table 3- the label "Percent of students in school who are White" should read "Proportion of students in school who are White." The data for this project were collected under a grant from the National Institute on Drug Abuse awarded to Dr. Ruth Edwards (R01 DA09349).

\section{Reference}

Snijders, T.A.B., \& Bosker, R. (1999). Multilevel analysis: An introduction to basic and advanced multilevel modeling. London, UK: Sage Publications.

The online version of the original article can be found at http://dx.doi. org/10.1007/s11121-009-0124-2.

\footnotetext{
K. L. Henry $(\bowtie) \cdot$ L. C. Harkabus $\cdot$ L. A. Chapin

Department of Psychology, Colorado State University,

Fort Collins, CO 80523-1876, USA

e-mail: kim.henry@colostate.edu

L. R. Stanley $\cdot$ R. W. Edwards

Tri-Ethnic Center for Prevention Research,

Colorado State University,

Fort Collins, CO 80523-1876, USA
} 